\title{
Tracheal Stenosis Presenting as Asthma Following Short-term Intubation
}

\author{
NK SARKAR ${ }^{\mathrm{a}}$, AA KIBRIA $^{\mathrm{b}}$
}

\begin{abstract}
:
Among different causes of acquired tracheal stenosis, endotracheal intubation is the commonest one. Though usually occurs after prolonged intubation or tracheostomy, tracheal stenosis may even develop following short duration of intubation. Patients commonly present with cough, wheeze, breathlessness and stridor which often mimics bronchial asthma, hence leads to a delay in diagnosis, as features may appear months to year after the procedure or even patients may remain undiagnosed especially when history is misleading. In this report we present a 28 -year-old
\end{abstract}

Introduction:

Tracheal stenosis is an unusual albeit serious complication of endotracheal intubation. Different studies reported that incidence of post-intubation and post-tracheostomy stenosis ranges from 10 to $22 \%{ }^{1,2}$ Though it's a consequence of prolonged intubation, airway stenosis is reported even after brief intubation. ${ }^{3}$ Patients commonly present with cough, wheeze, breathlessness and stridor. These symptoms may not initially suggest an airway stenosis and may be misdiagnosed as asthma, especially when there is a lack of representative history. By the time of symptomatic presentation, the stenosis may progress to a stage of critical narrowing which warrants emergency procedure.

\section{Case study:}

A 28-year-old lady presented with six months' history of dry cough and breathlessness.Cough had no diurnal variation; breathlessness, which was initially on exertion, later she felt at rest. She complained occasional

a. Dr. Nirmal Kanti Sarkar, Assistant Professor, Department of Respiratory Medicine, Mugda Medical College, Mugda, Dhaka - 1214.

b. Dr. Anwarul Anam Kibria, Associate Professor, Department of Thoracic Surgery, National Institute of Diseases of the Chest and Hospital, Mohakhali, Dhaka - 1212.

Address of Correspondence: Dr. Nirmal Kanti Sarkar, FCPS (Medicine), MD (Chest Diseases), FCCP, Assistant Professor, Department of Respiratory Medicine, Mugda Medical College, Mugda, Dhaka - 1214, Bangladesh. Phone: +8801711461925, E-mail: nirmalsarker@gmail.com

Received: 28 June, 2020

Accepted: 24 May, 2021 lady having an untold history of endotracheal intubation with asthma-like features who was getting treatment accordingly. With a gradually deteriorating clinical condition, she underwent our consultation. Repeated history, review of previous medical records, and necessary investigations made us establishing the confirmatory diagnosis. Prompt intervention relieved her symptoms.

Key words: Asthma, esophageal dilator, endotracheal intubation, fiberoptic bronchoscopy, tracheal stenosis

(J Bangladesh Coll Phys Surg 2021; 39: 205-208) DOI: https://doi.org/10.3329/jbcps.v39i3.54167

wheezes but no haemoptysis, chest pain, nasal discharge and there was no known history of allergy or childhood asthma. Initially she was seen by a primary care physician and later on by pulmonologist and was diagnosed clinically as a case of asthma. Treatment was started with inhaled corticosteroid, inhaled short acting bronchodilator and montelukast. After a brief period of improvement, she again developed symptoms. Two months before presentation, she had had persistent cough, wheeze and breathlessness at rest.

On examination, she looked anxious and was dyspnoeic. Pulse rate 112/minute, BP 110/85 mmHg, respiratory rate 21 breaths/minute, BMI $32.4 \mathrm{~kg} / \mathrm{m}^{2}, \mathrm{SpO}_{2} 94 \%$ at room air and inspiratory wheezes on chest auscultation. A chest X-ray was unremarkable. Rescue short course oral corticosteroid was started along with ongoing medications as OPD basis and use of inhaler medication technique was reviewed. A pulmonary function test was advised.

Three days later, she presented with worsening dyspnea and inspiratory stridor. Spirometry tracing showed a plateau in both inspiratory and expiratory phase of flowvolume loop (figure-1), features consistent with fixed airway obstruction. Patient was thus re-evaluated.

On repeat history taking she denied sleep disordered breathing or neck surgery. Neck glands were not enlarged and there was no palpable neck swelling, Pemberton's sign was negative. On query, her husband disclosed that she got admitted to the intensive care unit two months before the first appearance of current 
symptoms after suicidal ingestion of benzodiazepine tablet. Reviewing of previous medical records revealed that she was on invasive mechanical ventilation for 36 hours due to type-I respiratory failure. A clinical diagnosis of post-intubation tracheal stenosis (PITS) was made, and we planned for diagnostic fiberoptic bronchoscopy. On bronchoscopic examination, a smooth web-like stenosis of trachea was noted at the level of $5^{\text {th }}$ tracheal ring (figure-2) without any tracheomalacia. The $5.5 \mathrm{~mm}$ outer diameter bronchoscope probe (Pentax, EB-1575K, Japan) could not be passed through the narrowed lumen. We referred the patient for opinion of thoracic surgical team The surgical team advised for urgent surgical intervention.

As the patient had critical airway narrowing causing stridor, emergency bronchoscopic dilation was then done via rigid bronchoscope (Karl Storz, Germany) under general anesthesia using variable sizes of esophageal dilators (Neoplex, France) (figure-3). Procedure was repeated one month later. As the patient refused any further intervention or surgery, she was discharged with advice of periodic follow-up. Well maintained luminal patency was noted upto second year of bronchoscopic evaluation (figure-4).

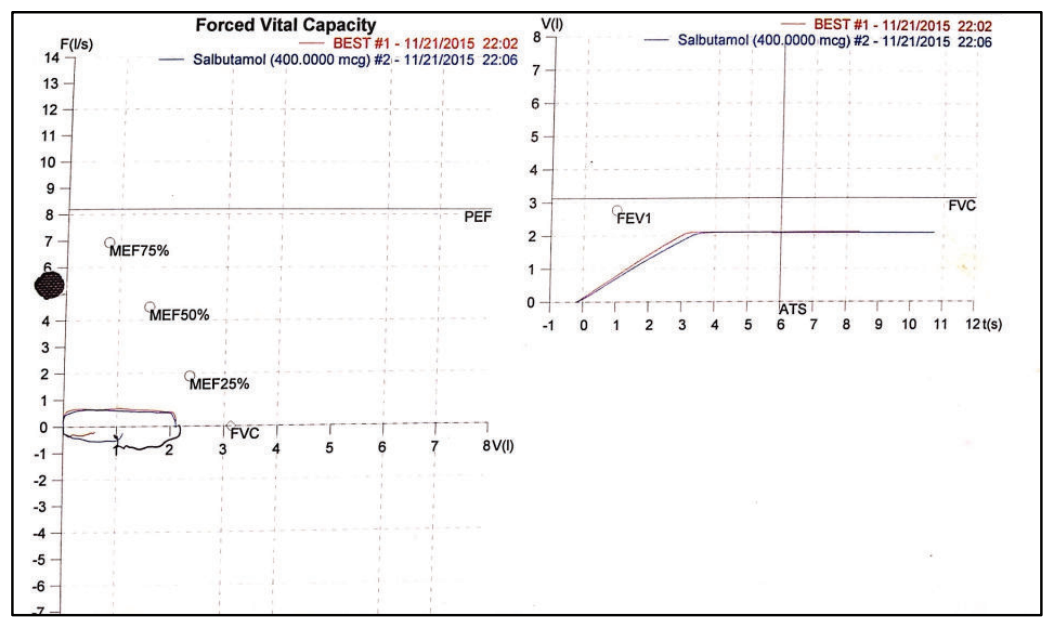

Fig.-1: Spirometry tracing (flow-volume loop) shows plateau in both phases of respiration-consistent with fixed airway obstruction.



Fig.-2: Bronchoscopic view of web-like tracheal stenosis (at presentation).

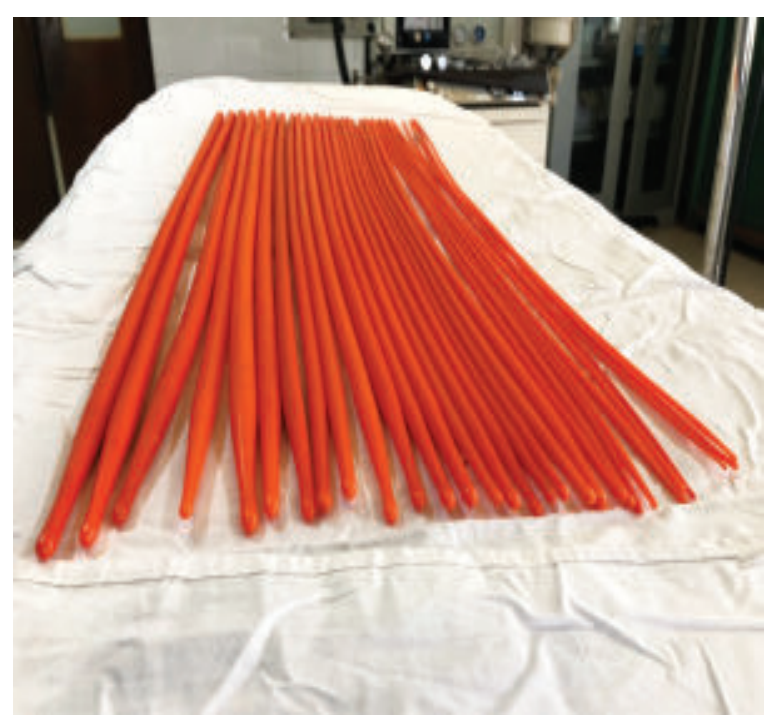

Fig.-3: Esophageal dilator 


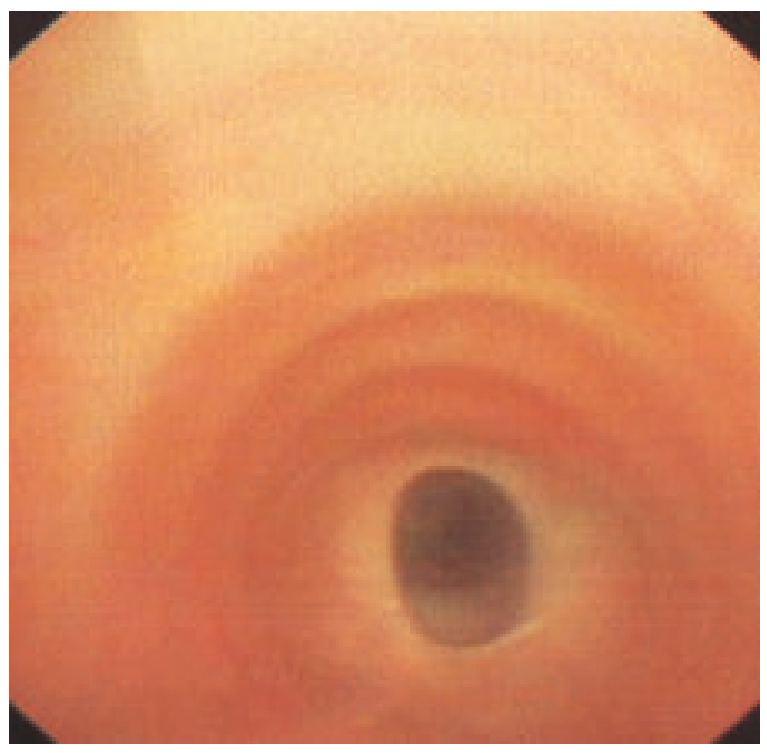

Fig.-4: Follow-up bronchoscopy 2 years later shows well-maintained tracheal patency.

\section{Discussion:}

Benign tracheal stenosis has different etiologies - trauma during surgery, intubation, tracheostomy, accident, flame burn or caustic injury of trachea, inflammatory diseases like Wegener's granulomatosis, sarcoidosis or systemic lupus erythematosus. ${ }^{4}$ The most common acquired cause is endotracheal intubation and tracheostomy. ${ }^{5}$ Post intubation tracheal stenosis (PITS) was first recognized by MacEwan in 1880, which he observed following prolonged intubation of four patients. ${ }^{6}$ Though rare if duration of intubation is less than a week, cases were reported following brief period of intubation. ${ }^{3}$

Post-intubation tracheal stenosis can occur anywhere from trachea adjacent to the tip of endotracheal tube upto glottis or subglottic region; most commonly at the location where tube cuff is in contact with tracheal wall. ${ }^{7}$ Typically trauma-induced tracheal stenosis occurs at glottis or subglottic region where the airway is narrowest. Our patient had stenosis at mid-trachea, where the endotracheal tube cuff is usually placed. This is the location of one-third cases of PITS. ${ }^{1}$ Capillary perfusion pressure of airway mucosa is $30 \mathrm{mmHg}$. When balloon pressure exceeds $25 \mathrm{mmHg}$, there is loss of regional blood flow on adjacent tracheal wall followed by local ischemia. ${ }^{8}$ The ischemic injury begins within $24-48$ hours of intubation, followed by healing with granulation tissue, resulting in web-like fibrosis within 3-6 weeks. ${ }^{9}$
Other predisposing factors include traumatic intubation, excessive movement of patient during intubation, history of previous intubation, excessive corticosteroid use, advanced age, female sex, severe respiratory failure, gastroesophageal reflux, obstructive sleep apnea, radiation therapy for laryngeal cancer. 3,10

Though gender influence is controversial, a predominance of female with tracheal stenosis has been reported in two series by Mehta et al. and McCaffrey et al. respectively. ${ }^{11,12}$ It has been postulated that estrogen increases the level of transforming growth factor ${ }^{2} 1$, promoting extracellular matrix production, including deposition of type I and III collagen, and finally fibrosis. ${ }^{7}$ Obesity may be a co-existing underlying condition. Zias et al. in a case series of 31 patients observed that $66 \%$ were obese. These patients have an increased neck circumference which may pose higher trauma during intubation or tracheostomy. ${ }^{7}$

Patients usually develop web-like stenosis following endotracheal intubation, as occurred in our patient. In their study, Zias et al. observed that among 11 patients with PITS, 9 (81\%) developed web-like stenosis, 1 (9\%) web-like stenosis with tracheomalacia and 1 (9\%) developed tracheomalacia. ${ }^{7}$

Bronchoscopy is an excellent tool for the diagnosis of PITS which entails the location, severity and length of stenosis. But if the lesion is critically narrow, and bronchoscope probe can't be passed through, CT scan of chest is helpful to determine the extent of lesion. ${ }^{13} \mathrm{But}$ as our patient couldn't lie flat due to severe respiratory distress, CT scan evaluation was not possible.

The management of PITS depends on site of damage, severity of stenosis, cause and presence of comorbidities. Surgical resection and end-to-end anastomosis is considered to be the definitive treatment for young patients without co-morbidities. ${ }^{11}$ For elderly or patients with significant co-morbidities, endoscopic approach should be considered. Rahaman et al. in a large case series of 115 patients shown that bronchoscopic treatment modalities can provide durable success rate in selected patients with a relatively low rate of complication. ${ }^{4}$ Historically, subglottic stenosis has been managed with dilation using Jackson dilator and rigid bronchoscope. For web-like stenosis, mucosal sparing technique with radial incision by argon plasma coagulation (APC), electrocautery or Nd:YAG laser 
followed by gentle dilation using tracheal balloon is a good option. ${ }^{11}$ Other modalities include tracheal stent, application of mitomycin $\mathrm{C}$ and brachytherapy. ${ }^{4,14}$ Stenotic lesion amenable to endoscopic management have several features - a) presence of an external cartilaginous ring, b) vertical length $<1 \mathrm{~cm}, \mathrm{c}$ ) noncircumferential, and d) strict tracheal localization. ${ }^{13}$ As our patient had severe symptoms and critical airway compromise (Meyer-Cotton grade-III), we opted for emergency bronchoscopic dilation as per institutional availability of equipment i.e. esophageal dilator. We could followed-up the patient for two years, and she didn't develop restenosis within this period - indicating that rigid bronchoscopic dilation is a good therapeutic option for PITS.

\section{Conclusion}

A patient with tracheal stenosis may present with asthma-like clinical features. As the complication develops following a certain period of extubation, patient sometimes overlook the history, or physician may not retrieve such an important clue - ultimately leads to misdiagnosis and a grave consequence, as happened to our patient. Optimum caution should be practiced during intubation to avoid airway injury. Also thorough history should be taken before final diagnosis, as "all that wheeze is not asthma". Esophageal dilator can be used successfully for management of such patients if there is no alternative.

\section{Conflict of interest}

There is no potential conflict of interest to declare.

\section{Disclosure}

Appropriate written informed consent was obtained for publication of this case report.

\section{Acknowledgement}

This case was presented at the $23^{\text {rd }}$ Congress of Asian Pacific Society of Respirology, Taipei, Taiwan, held on 29 November-2 December 2018.

\section{References:}

1. Grillo HC, Donahue DM, Mathisen DJ, Wain JC, Wright CD. Post-intubation tracheal stenosis. Treatment and results. J Thorac Cardiovasc Surg. 1995; 109: 486-93. https:/ /doi.org/10.1016/S0022-5223(95)70279-2

2. Stauffer JL, Olson DE, Petty TL. Complications and consequences of endotracheal intubation and tracheostomy. A prospective study of 150 critically ill adult patients. Am
J Med. 1981; 70 (1): 65-76. https://doi.org/10.1016/00029343(81)90413-7

3. Yang KL. Tracheal stenosis after a brief intubation. Anesth Analg. 1995; 80: 625 https://doi.org/10.1097/00000539199503000-00037.PMid:7864440

4. Rahman NA, Fruchter O, Shitrit D, Fox BD, Kramer MR. Flexible bronchoscopic management of benign tracheal stenosis: long term follow-up of 115 patients. J Cardiothorac Surg. 2010; 5:2. https://doi.org/10.1186/17498090-5-2.PMid:20078894,PMCid:PMC2822773

5. Grillo HC, Donahue DM. Post intubation tracheal stenosis. Semin Thorac Cardiovasc Surg. 1996; 8: 370-80.

6. MacEwan W. Clinical observations on the introduction of tracheal tube by the mouth instead of performing teracheotomy or laryngotomy. Br Med J. 1880; 2: 122-24. https://doi.org/10.1136/bmj.2.1021.122.PMid:20749630, PMCid:PMC2241154

7. Zias N, Chroneou A, Tabba MK, Gonzalez AV, Gray AW, Lamb CR, et al. Post tracheostomy and post intubation tracheal stenosis: Report of 31 cases and review of the literature. BMC Pulm Med. 2008; 8:18.https://doi.org/ 10.1186/1471-2466-8-18.PMid:18803874, PMCid:PMC 2556644

8. Weymuller EA Jr. Laryngeal injury from prolonged endotracheal intubation. Laryngoscope. 1988; 98: 115.https://doi.org/10.1288/00005537-19880800100001.PMid:3398673

9. Wain JC Jr. Post intubation tracheal stenosis. Semin Thorac Cardiovasc Surg. 2009; 21: 284-89. https://doi.org/10.1053/ j.semtcvs.2009.08.001.PMid:19942129

10. Koshkareva Y, Gaughan JP, Soliman AM. Risk factors for adult laryngotracheal stenosis: a review of 74 cases. Ann Otol Rhinol Laryngol. 2007; 116(3): 206-10. https:// doi.org/10.1177/000348940711600308.PMid:17419525

11. Mehta AC, Lee FYW, Cordasco EM, Kirby T, Eliachar I, Boer GD.. Concentric tracheal and subglottic stenosis. Management using the Nd-YAG laser for mucosal sparing followed by gentle dilatation. Chest. 1993; 104: 67377.https://doi.org/10.1378/chest.104.3.673. PMid: 8365273

12. McCaffrey TV. Classification of laryngotracheal stenosis. Laryngoscope. 1992; 102: 1335-40. https://doi.org/ 10.1288/00005537-199212000-00004.PMid:1453837

13. Colt H, Murgu S, editors. Post intubation tracheal stenosis. In: Bronchoscopy and central airway disorders: A patient centered approach. Philadelphia, Elsevier Saunders, 2012: 95-104.

14. Melkane A, Matar NE, Haddad AC, Nassar MN, Almoutran HG, Rohayem Z, et al. Management of postintubation tracheal stenosis: Appropriate indications make outcome differences. Respiration. 2010; 79: 395-401.https://doi.org/ 10.1159/000279225. PMid:20110646 